\title{
Pigeons' memory for event duration: Differences between visual and auditory signals
}

\author{
ANGELO SANTI, LIANNE STANFORD, and JAMES COYLE \\ Wilfrid Laurier University, Waterloo, Ontario, Canada
}

\begin{abstract}
In Experiment 1, pigeons were trained to discriminate short $(2 \mathrm{sec})$ and long $(8 \mathrm{sec})$ durations of tone by responding to red and green comparison stimuli. During delay testing, a systematic response bias to the comparison stimulus correct for the long duration occurred. Tests of responding without the tone reduced accuracy on long-sample trials but not on short-sample trials suggesting that the pigeons were attending to the tone and not simply timing the total trial duration. The pigeons were then trained to match short $(2 \mathrm{sec})$ and long $(8 \mathrm{sec})$ durations of light to blue/yellow comparisons. During delay testing, "choose-long errors" occurred following tone durations, but "choose-short errors" occurred following light durations. In Experiment 2, accuracy was assessed on test trials in which the tone and the light signals were simultaneously presented for the same duration or for different durations. $\mathrm{Pi}$ geons responded accurately to durations of light, but were unable to accurately respond to durations of tone simultaneously presented with the light. The data from Experiment 1 suggest that there are important differences between light and tone signals with respect to the events that control the termination of timing. The data from Experiment 2 indicate that pigeons cannot simultaneously time visual and auditory signals independently and without interference. Consequently, they are inconsistent with the idea that there is a single internal clock that times both tone and light durations.
\end{abstract}

Research on the perception of time in humans has demonstrated that an important role is played by stimulus factors (Allan, 1979; Block, 1990; Goldstone \& Lhamon, 1974; Grondin, 1993; Poynter, 1989). For some time, it has been recognized that stimulus factors may be likewise important in animals' temporal judgments (Fetterman, 1996; Stubbs, Dreyfus, \& Fetterman, 1984). The accuracy of temporal discriminations in animals is affected by stimulus modality (Meck, 1984; W. A. Roberts, Cheng, \& Cohen, 1989; Stubbs et al., 1984), stimulus intensity (Kraemer, Brown, \& Randall, 1995; Wilkie, 1987), duration of food access versus light duration (Spetch \& Wilkie, 1982), and empty versus filled intervals (Kraemer, Randall, \& Brown, 1997; Mantanus, 1981). Stimulus factors may also play a role in an animal's memory for duration.

In pigeons, when memory for event duration is examined with a choice procedure, the typical finding is a choose-short effect (Spetch, 1987; Spetch \& Rusak, 1989, 1992; Spetch \& Wilkie, 1982, 1983). That is, when variable-length delay intervals are presented following temporal samples, pigeons show an increasing tendency to peck the comparison stimulus corresponding to the short-

This research was supported by a grant from the Natural Sciences and Engineering Research Council of Canada (OGPOOD6378). The authors thank Marion Corrick for her technical assistance, and Lori Ross and Devin Mueller for assisting with some of the data collection for Experiment 1. Lianne Stanford is now in the Psychology and Neuroscience Program at Dalhousie University. Correspondence should be addressed to A. Santi, Department of Psychology, Wilfrid Laurier University, Waterloo, ON, Canada N2L 3C5 (e-mail: asanti@machl.wlu.ca). duration sample. However, when memory for event duration is examined in rats with a choice procedure, the typical finding is a choose-long effect (Berz, Battig, \& Welzl, 1992; Church, 1980, Experiment 3B; Meck, Church, \& Olton, 1984; S. Roberts, 1982; Santi, Stanford, \& Coyle, 1997; Santi, Weise, \& Kuiper, 1995). That is, rats show an increasing tendency to make the comparison response appropriate for the long-duration sample. This difference in response biases during delay testing could be due to differences in the stimulus that is used to stop the internal clock. In pigeons, it appears that offset of the signal being timed stops the clock. In rats, however, offset of the signal does not necessarily stop the clock. In studies in which choice responding is exclusively based on the spatial location of the levers, delaying the entry of the levers into the chamber increases the probability of responding "long" following the short-duration sample (Berz et al., 1992; Church, 1980, Experiment 3B; Meck et al., 1984; S. Roberts, 1982). In studies in which choice responding is based on visual or auditory discriminative cues, the stimulus used to stop the clock may depend on the modality of the signal and the modality of the cue. When the modalities differ, as in a "tone signal-visual choice cue" group (Santi et al., 1995) or a "light signal-tone choice cue" group (Santi et al., 1997), rats appear to use the onset of choice cues to stop the clock rather than the offset of the signal. On the other hand, when the modalities are the same as in a "visual signalvisual choice cue" group (Santi et al., 1995), rats appear to use the offset of the signal itself to stop the clock. This is the only condition in which a choose-short effect has been reported in rats. In pigeons, all of the research on 
memory for event duration has employed visual signals and visual choice stimuli, and choose-short effects are normally found when a choice procedure is used.

The present experiments were conducted to assess whether memory for event duration in pigeons is affected by the modality of the signal and its relationship to the modality of the choice cues. Pigeons were trained to match short and long durations of tone to one set of color comparisons and the same durations of light to a different set of color comparisons (Experiment 1 ). If a shift in modality between the signal and choice cues has the same effect in pigeons as in rats, then, during delay testing, choose-long errors would be expected following tone signals and choose-short errors would be expected following light signals. In Experiment 2, we assessed whether pigeons could simultaneously time visual and auditory signals and selectively retrieve the duration of either from working memory. Accurate responding under these conditions would support the hypothesis that visual and auditory signals are timed by the same internal clock (S. Roberts, 1982; S. Roberts \& Church, 1978; W. A. Roberts et al., 1989). An inability to time simultaneously presented visual and auditory signals independently and without interference would be inconsistent with this hypothesis.

\section{EXPERIMENT 1}

Pigeons were trained to discriminate short (2-sec) and long $(8-\mathrm{sec})$ durations of tone by responding to red and green comparison stimuli. During delay testing, the interval between tone offset and presentation of the comparison stimuli was varied $(0,1,3$, and $9 \mathrm{sec})$. Following delay testing, additional tests were conducted in which the tone was omitted on some trials in order to determine whether the pigeons were actually attending to the tone or simply timing the total duration of a trial. The pigeons were then trained within sessions to match short (2-sec) and long (8$\mathrm{sec})$ durations of tone to red/green comparisons and the same durations of light to blue/yellow comparisons. Additional delay tests were conducted. If a change in stimulus modality, between the signal and the choice cues, affects memory for event duration in pigeons in the same way as it does in rats, choose-long errors would be expected following the tone durations, but choose-short errors would be expected following the light durations.

\section{Method}

\section{Subjects}

Seven White Carneaux pigeons maintained at approximately $80 \%$ of their ad-lib weights and housed individually with constant access to grit and water served as subjects. The colony room was illuminated on a 12:12-h light:dark cycle by fluorescent lights. All of the birds had prior experience in experiments that involved discrimination of visual stimuli.

\footnotetext{
Apparatus

Three touchscreen testing stations, located in individual test rooms, were used. Each test station consisted of a clear Plexiglas
}

cage ( $30 \mathrm{~cm}$ wide $\times 40 \mathrm{~cm}$ deep $\times 36 \mathrm{~cm}$ high) with a large opening cut into the one end wall, which was constructed of stainless steel. On both the left and the right sidewalls of the cage, adjacent to the end with the large opening, was a $5.7 \times 5 \mathrm{~cm}$ opening that provided access to a hopper filled with mixed grain (Coulbourn Model E1410). A ceiling fan provided ventilation. A color SuperVGA monitor (Mitsubishi SD4311C) with an attached touch frame (Carrol Touch, Frame 8100-9583-01, Card 8200-3224-01) was placed against the opening in the stainless steel wall. An IBM-compatible microcomputer located in the same room controlled the stimulus displays, recorded peck location, and operated the feeders.

\section{Procedure}

Each trial was initiated by onset of a $1325-\mathrm{Hz}$ tone, which was generated through the speaker of the microcomputer. The speaker was adjacent to the touchscreen testing apparatus. The frequency of the tone was the same as that which W. A. Roberts et al. (1989) and Cheng and W. A. Roberts (1989) used successfully to study timing in pigeons. The intensity of the tone as measured with a Radio Shack digital sound-level meter (33-2055) from the interior of the Plexiglas cage was $68 \mathrm{~dB}$ in one room and $60 \mathrm{~dB}$ in the other two rooms. The distance from the microcomputer to a point in the test cage directly in front of the center of the touchscreen ranged from 43.2 to $55.9 \mathrm{~cm}$ in the three rooms. The tone was presented for 2 or $8 \mathrm{sec}$. Termination of the signal was followed immediately by the presentation of the color comparison stimuli (red and green fields). The comparison colors were presented in two rectangular response areas, each measuring $3.4 \times 3.2 \mathrm{~cm}$ (width $\times$ height), one on the left and one on the right side of the monitor $(15.6 \mathrm{~cm}$ apart as measured from their inside edges). Position of the color comparison stimuli was counterbalanced over trials. For 4 birds, a response to the green comparison was correct following a 2-sec tone, and a peck to the red comparison was correct following an 8-sec tone. For the remaining 3 birds, the relationship between the signal duration and the correct comparison stimulus was reversed. A single response to one of the comparison stimuli turned them off and, if correct, provided $3 \mathrm{sec}$ of access to mixed grain randomly presented at either the left or the right hopper openings. Incorrect responses to the comparison stimuli produced a 3-sec blackout, followed immediately by presentation of the same signal duration and comparison stimulus configuration. A correct response on a correction trial produced $3 \mathrm{sec}$ of access to mixed grain, although only the choice response on the initial (noncorrection) trial was used to calculate matching accuracy. When necessary, supplementary feedings of Purina Pigeon Chow occurred after the experimental sessions and on days when the birds were not run. Within each block of four trials, all combinations of the two signal durations with red and green comparison stimuli on the left and right response areas occurred once. The order of presentation was randomized individually for each bird. All birds received 120 trials per session. The intertrial interval (ITI) was a constant $10 \mathrm{sec}$.

Delay testing with tone signals. Following 45 sessions of training, delay testing was conducted for 10 sessions. Each test session consisted of 144 trials, within which 48 trials for each signal duration occurred at the 0 -sec delay and 8 trials for each sample occurred at each of the other delays $(1,3$, and $9 \mathrm{sec})$. This distribution of delays was used so that the reference memory of durations and their associations with the comparison stimuli established during 0 -sec delay training would remain relatively stable during testing (Spetch \& Wilkie, 1983). There was no illumination in the test chamber during the delay intervals. The correction procedure remained in effect on 0 -sec delay trials, but not on trials with delays of 1,3 , or $9 \mathrm{sec}$. All other parameters were the same as those described previously.

Testing with no tone signals. Following delay testing, the birds received five sessions, in which 108 of the 144 trials were baseline trials identical to those which preceded delay testing. On the re- 
maining 36 trials, the tone signal was omitted and additional time was added to the ITI. That is, on half of these test trials, $2 \mathrm{sec}$ were added to the ITI, and on the other half, $8 \mathrm{sec}$ were added to the ITI. One test trial occurred randomly within each block of four trials. On test trials, a response either to the left or to the right response area was reinforced by access to mixed grain with a probability of 5 .

Training and delay testing with tone and light signals. Following testing, the birds were given seven sessions of baseline training with tone signals alone, and then the birds were trained with both tone and light signals. Each trial began with the presentation of one of four different sample stimuli. On half of the trials, the signal consisted of presentation of the tone for either 2 or $8 \mathrm{sec}$. On the remaining trials, the sample consisted of a light for either 2 or $8 \mathrm{sec}$. The light signal was a homogeneous gray square $3.3 \times 3.3 \mathrm{~cm}$ presented in the central area of the monitor (approximately $12 \mathrm{~cm}$ from the left and right bezel as measured to the nearest edge). Red and green comparisons were presented after the tone signal, and blue and yellow comparisons were presented after the light signal. The response contingencies following tone signals were the same as they had been previously. If red had previously been correct following the 2-sec tone signal, yellow was correct following the 2-sec light signal. If green had previously been correct following the 2 -sec tone signal, blue was correct following the $2-\mathrm{sec}$ light signal. Within each block of eight trials, all combinations of the four sample stimuli (two signal carriers $\times$ two sample durations) and the two comparison stimulus configurations occurred once. The order of presentation was randomized individually for each bird. All birds received 144 trials per session. All other parameters were the same as those described previously. Each bird received 40 sessions of training.

Each delay testing session consisted of 144 trials. Twenty-four trials for each of the four sample stimuli occurred at the 0 -sec delay and four trials for each sample occurred at each of the other delays $(1,3$, and $9 \mathrm{sec})$. This distribution of delays was used so that the reference memory of durations and their associations with the comparison stimuli established during $0-\mathrm{sec}$ delay training would remain relatively stable during testing (Spetch \& Wilkie, 1983). There was no illumination in the test chamber during the delay intervals. The correction procedure remained in effect on 0 -sec delay trials, but not on trials with delays of 1,3 , or $9 \mathrm{sec}$. All other parameters were the same as those described previously. Each bird received 15 sessions of delay testing. The level of significance used for all statistical tests was $p<.05$.

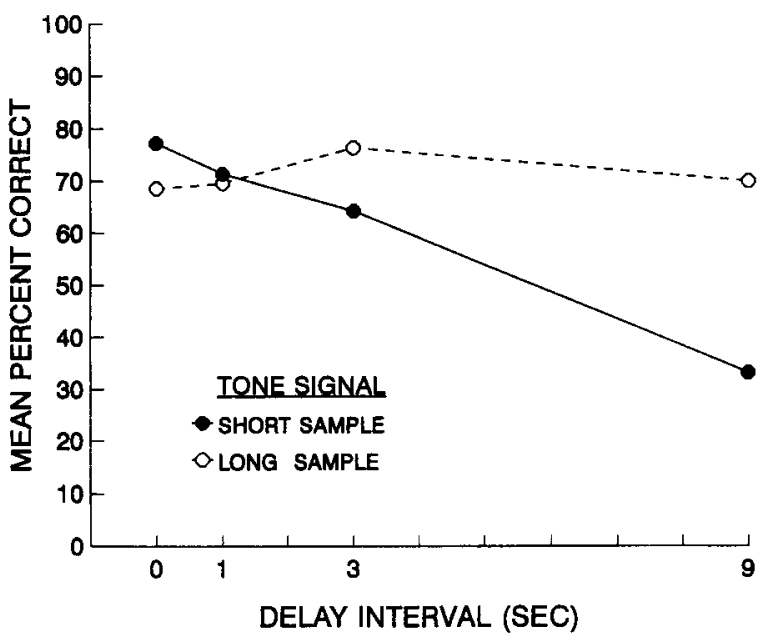

Figure 1. Mean percentage of correct responses during delay testing for short and for long durations of tone.

\section{Results and Discussion}

The mean percentage of correct matching accuracy during the initial delay tests with tone signals alone is shown in Figure 1. Accuracy dropped much more on shortsample trials than on long-sample trials as the delay increased. An analysis of variance (ANOVA) conducted on these data indicated significant main effects of signal duration $[F(1,6)=12.07]$ and delay $[F(3,18)=45.85]$, as well as a signal duration $\times$ delay interaction $[F(3,18)=$ $8.00]$. Increasing the delay significantly reduced accuracy on short-sample trials $[F(3,18)=22.02]$, but it had no effect on long-sample trials $(F<1)$. At the 0 -sec delay, accuracy was significantly higher on short-sample trials than on long-sample trials $[F(1,6)=6.41]$. However at both the 3-sec delay and the 9-sec delay, accuracy was greater on long-sample trials than on short-sample trials $[F(1,6)=13.13$ and 10.93 , respectively $]$.

The choose-long response bias observed during delay testing could have occurred if the birds failed to attend to the tone and simply timed the interval from the end of one trial to the presentation of comparison stimuli on the next trial (i.e., total duration of the trial). Thus, during baseline trials, the shorter interval being timed would have been $12 \mathrm{sec}(10$-sec ITI +2 -sec tone) and the longer interval would have been $18 \mathrm{sec}$. A great deal of evidence indicates that the point of subjective equality between two intervals is at the geometric mean. If the intervals being timed were $12 \mathrm{sec}$ and $18 \mathrm{sec}$, the PSE would be approximately $14.7 \mathrm{sec}$. When a 2 -sec sample was presented, the birds were $55 \%$ correct (close to indifferent between responding short or long) following a 3-sec delay. This would be consistent with an internal clock reading approximately equivalent to the PSE on trials consisting of a 10-sec ITI + 2-sec signal $+3-\sec$ delay $=$ $15 \mathrm{sec}$, suggesting that the birds may have been timing two intervals, a shorter one of $12 \mathrm{sec}$ and a longer one of $18 \mathrm{sec}$ (i.e., not attending to the tone at all).

A direct test of this interpretation is to present the birds with trials in which no tone is presented but with an additional amount of time added to the ITI. If performance is not disrupted by the absence of the tone, this would support the notion that the birds are simply timing the total duration of the trial. If performance is disrupted, birds are attending to the tone and not simply timing the total duration of a trial.

The mean percent correct choice during testing is shown in Figure 2. On baseline trials when the tone signal was presented, accuracy was slightly above $70 \%$ correct following both the short and long samples. Accuracy remained high on short-sample trials, when the tone was not presented, but it fell substantially on long-sample trials when the tone was absent. Although overall accuracy did not differ significantly on tone and no-tone trials $[F(1,6)=3.56]$, the interaction of signal duration $X$ trial type was statistically significant $[F(1,6)=8.58]$. When the tone was presented, there was no difference between accuracy for short and for long samples $[F(1,6)=$ 


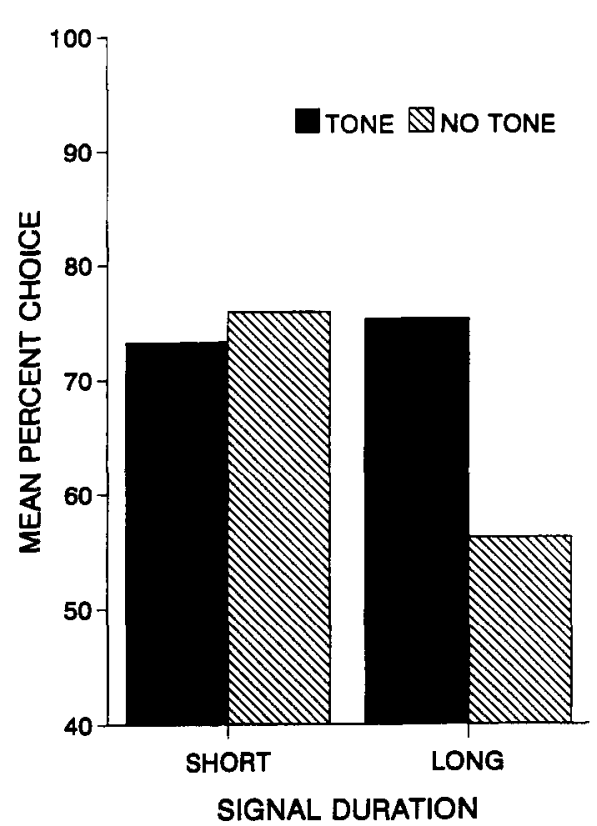

Figure 2. Mean percentage of correct responses during trials in which the short and the long tone signal were presented and those in which they were omitted.

1.32]. However, when the tone was not presented, accuracy was significantly lower on long-sample trials than on short-sample trials $[F(1,6)=6.29]$. Thus it appears that omitting the tone produced a large shift in response bias without a significant reduction in overall accuracy. The choose-long bias obtained in the previous delay test cannot be explained by claiming that the birds were timing the total trial duration and not attending to the tone.

The mean percentages of correct matching accuracy during the delay tests with both tone and light signals are shown in Figure 3. For tone signals, a choose-long bias was observed. Accuracy declined more on short-sample trials than on long-sample trials as the delay increased. For light signals, a choose-short bias was observed. Accuracy dropped much more on long-sample trials than on short-sample trials as the delay increased. An ANOVA conducted on these data indicated a significant main effect of delay $[F(3,18)=46.77]$ as well as significant interactions of signal modality $\times$ signal duration $[F(1,6)=$ $11.71]$, signal modality $\times$ delay $[F(3,18)=7.51]$, and signal modality $\times$ signal duration $\times$ delay $[F(3,18)=$ 18.39]. The interaction of signal duration $X$ delay was statistically significant both when the signal was the tone $[F(3,18)=9.04]$, and when it was the light $[F(3,18)=$ $6.48]$. When the signal was the tone, accuracy dropped on short-sample trials $[F(3,18)=25.01]$, but not on long-sample trials $(F<1)$, as the delay increased. Accuracy was significantly greater on long-sample trials than on short-sample trials at both the 3-sec and the 9-sec de- lays $[F(1,6)=10.02$ and 7.53]. When the signal was the light, accuracy dropped much more on long-sample trials $[F(3,18)=30.35]$ than on short-sample trials $[F(3,18)=$ $5.43]$ as the delay increased. In addition, accuracy was significantly greater on short-sample trials than on longsample trials at both the 3 -sec and 9-sec delays $[F(1,6)=$ 6.71 and 8.12].

These data are the first to show markedly different response biases at delays greater than the baseline delay in the same subject timing nominally similar signal durations. In previous research with rats, the choose-long bias obtained during delay testing was attributed to the nature of the event that stops the internal clock (Santi et al., 1997; Santi et al., 1995). Similarly in the present study with pigeons, it could be that the stimulus controlling the termination of timing on a trial differs for visual and auditory event durations. The relationship between the modality of the signal and the modality of the choice cues may be an important variable. On the basis of the currently available data in rats and pigeons, when there is no shift in modality, termination of timing appears to be strongly controlled by termination of the signal itself.
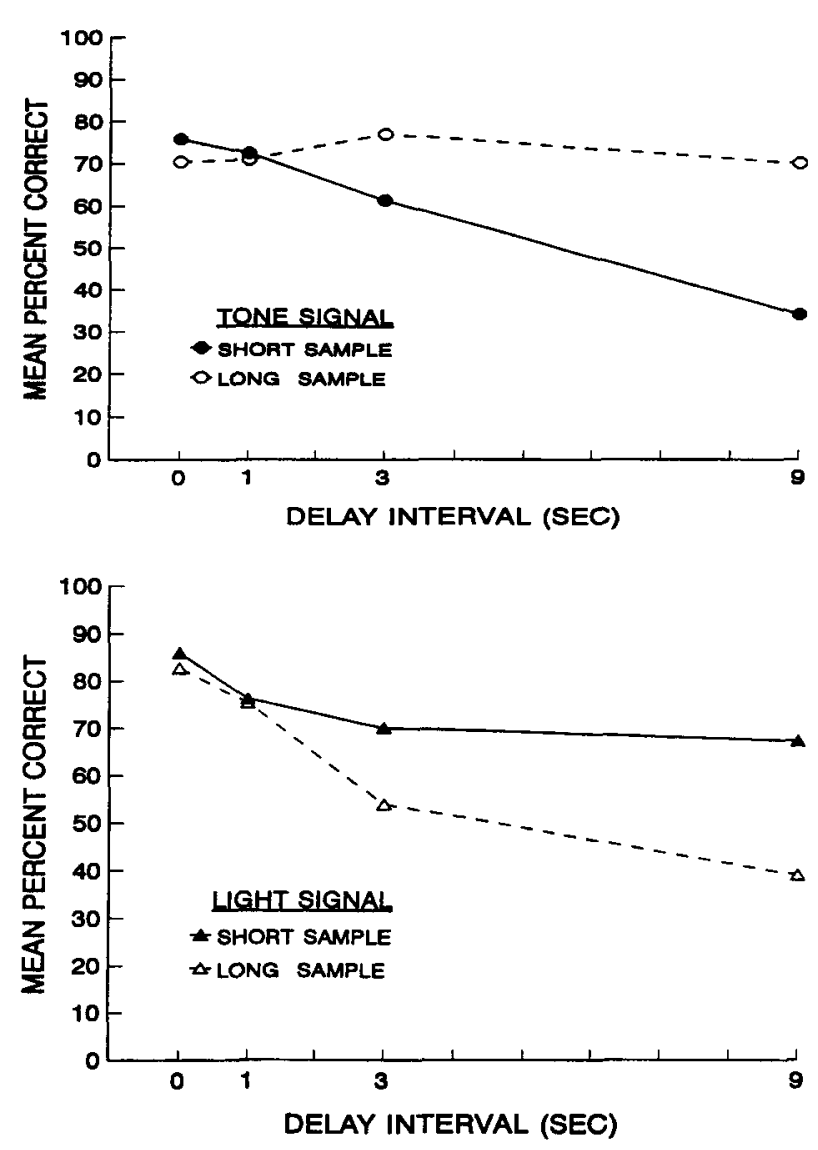

Figure 3. Delay testing data for short and long sample durations as a function of the modality of the signal: tone in the top panel and light in the bottom panel. 
However, when there is a shift in modality between the signal and the choice cues, termination of the signal by itself does not appear to result in the clock's being stopped. The presentation of choice cues from another modality may be a more salient event which comes to control termination of timing. Consequently, on auditory event duration trials, in the present experiment, the onset of light comparisons in a dark chamber may have overshadowed the offset of the tone and controlled the termination of timing. Additional research with auditory comparison stimuli would be useful in obtaining a more complete understanding of the relationship between signal modality and choice cue modality.

\section{EXPERIMENT 2}

Experiment 1 demonstrated important differences in memory for event duration when auditory signals and light signals are mapped onto different sets of visual choice cues. In Experiment 2, we examined whether pigeons would be able to simultaneously time visual and auditory signals and selectively retrieve the duration of either from working memory. Pigeons were presented with intermittent test trials in which both an auditory event and a visual event were simultaneously presented. On some test trials, the event durations were the same, and on other test trials, they differed. On trials in which they differed, the short-duration signal was always presented in the final $2 \mathrm{sec}$ of the long-duration signal.

Previous research based on modality shift experiments suggests that both rats (S. Roberts, 1982; S. Roberts \& Church, 1978) and pigeons (W. A. Roberts et al., 1989) use the same internal clock to time auditory and visual signals. According to these findings, animals form an amodal and abstract representation of stimulus duration and the associations between reinforced comparison responses and duration. These results suggest that on test trials consisting of the simultaneous presentation of an auditory event and a visual event of exactly the same duration, accurate responding should occur regardless of whether the comparison stimuli appropriate for the auditory or the visual event are presented. This result should occur because even if the birds timed only one of the signals on these trials, the amodal and abstract representation of that duration should be able to serve as a discriminative stimulus for either set of comparisons.

In addition, Meck and Church (1984) demonstrated that rats can simultaneously time auditory and visual signals independently and without interference. If pigeons have a similar capability, then, on trials consisting of the simultaneous presentation of different auditory and visual event durations, accurate responding on tests of either duration should be observed. Previous research demonstrating that rats and pigeons can simultaneously process temporal and numerical information (Meck \& Church, 1983; W. A. Roberts \& Mitchell, 1994) suggests that both species have the cognitive capacity for parallel processing in tasks requiring use of an internal clock.

\section{Method}

\section{Subjects and Apparatus}

The subjects and apparatus were the same as those used in Experiment 1 .

\section{Procedure}

Following the delay interval testing conducted in Experiment 1, the birds were given two sessions of baseline training consisting of 144 trials as previously described. The birds were then given 10 sessions of testing which consisted of 144 trials. Two thirds of these trials were the same as baseline training trials. Either the tone or the light was presented for 2 or $8 \mathrm{sec}$. On one sixth of the trials, both the tone and the light were simultaneously presented for the same duration (either 2 or $8 \mathrm{sec}$ ). On the remaining one sixth of the trials, both the tone and the light were presented for different durations. One was presented for $2 \mathrm{sec}$, and the other, for $8 \mathrm{sec}$. The shorter event was always presented during the last $2 \mathrm{sec}$ of the longer event. On one half of all of the test trials, the comparisons associated with the tone were presented (red/green), whereas on the other half of the test trials, those associated with the light were presented (yellow/blue). Correct responses were reinforced with $3 \mathrm{sec}$ of access to mixed grain randomly presented at either the left or the right hopper openings. Incorrect responses produced a 3-sec blackout. The correction procedure described in Experiment 1 remained in effect only on regular training trials, not on test trials. The level of significance used for all statistical tests was $p<.05$.

\section{Results and Discussion}

The mean percent correct matching performance during test sessions is presented in Figure 4. The data for trials in which the duration of the tone signal was tested are shown in the top panel of the figure. When the tone signal was presented by itself, accuracy was equivalent on short- and long-sample baseline trials. Simultaneously presenting the light signal for the same duration as that of the tone signal reduced the accuracy of tone duration discrimination, but only when the sample duration was long, not when it was short. Accuracy of the tone duration discrimination declined to chance levels when a long tone and long light were simultaneously presented. When a light duration was presented which was different from the tone duration, accuracy of the tone duration discrimination declined on both short- and long-sample trials. Not only did the short duration of light interfere with correctly classifying the long tone duration, it appeared to produce approximately the same degree of disruption as did the long duration of light on same trials. In other words, correctly classifying the tone duration as long was equally disrupted by the presentation of $2 \mathrm{sec}$ of light in the final $2 \mathrm{sec}$ of tone and by the presentation of the light throughout the tone. An ANOVA of the data for trials involving tests of the tone duration revealed a significant main effect of trial type $[F(2,12)=32.36]$ and a significant trial type $\times$ signal duration interaction $[F(2,12)=$ 5.33]. When the short tone duration was tested, there was no difference between baseline and same trials $(F<1)$, but accuracy was significantly lower on different trials than on baseline trials $[F(1,6)=22.63]$. On the long tone duration trials, accuracy was significantly lower on same and on different trials in comparison with baseline trials $\left[F_{\mathrm{s}}(1,6)=7.19\right.$ and 6.29 , respectively $]$. 

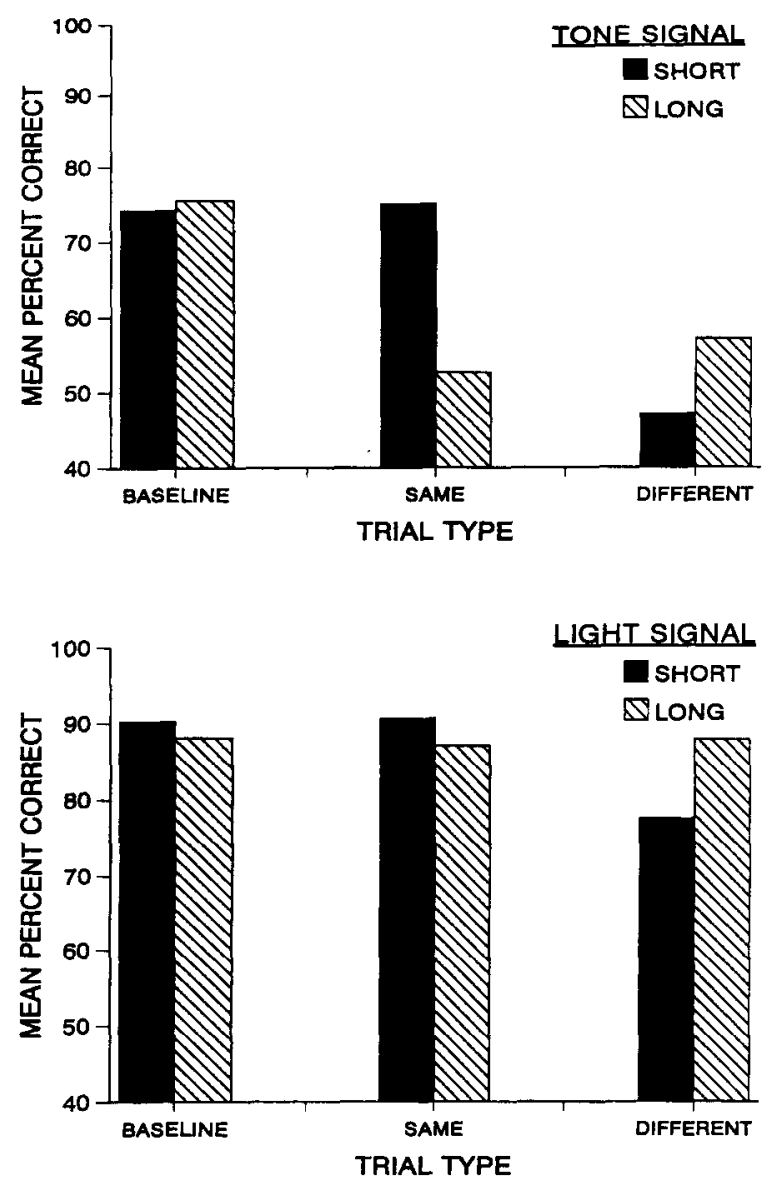

Figure 4. Mean percentage of correct responses as a function of trial type. On baseline trials, either the tone or the light was presented alone. On same trials, both the tone and the light signal were simultaneously presented for the same duration. On different trials, both the tone and the light signal were simultaneously presented for different durations. The trials for which the duration of the tone signal was tested are presented in the top panel, and the trials for which the duration of the light signal was tested are presented in the bottom panel.

The data for trials in which the duration of the light signal was tested are shown in the bottom panel of Figure 4 . Accuracy remained uniformly high across the various trial types, except in the case of the short light duration on different trials. An ANOVA of the data for trials involving tests of light duration revealed a significant main effect of only trial type $[F(2,12)=7.53]$. The trial type $\times$ sample duration interaction was not statistically significant $[F(2,12)=2.97]$. When the light duration was tested, there was no difference in accuracy between baseline and same trials $(F<1)$. Accuracy was significantly lower on different trials than on baseline trials, however $[F(1,6)=7.53]$.

Overall, judgment of duration signaled by light was not strongly affected by the simultaneous presentation of a tone. Only when the tone duration was different from the light duration was there any evidence of disruption, but accuracy remained well above chance on these trials.
On the other hand, judgment of tone duration was usually reduced to chance levels by the simultaneous presentation of light, except when both the tone and the light were presented for the short duration. The failure of the light to affect judgment of tone duration at the shortsample duration is not surprising, given that in Experiment 1 it was found that omitting the tone entirely affected accuracy only on long-sample trials.

When either 2 or $8 \mathrm{sec}$ of light and an 8 -sec tone were presented simultaneously, pigeons tested for tone duration responded as if no tone had been presented at all. The result for the 8-sec tone 8-sec light condition is similar to Kraemer and W. A. Robert's (1985) finding that pigeons cannot successfully match tones of different frequencies when a light is simultaneously being presented. In their study as well as this one, it appears as if the pigeons had almost no awareness of the tone when it was presented along with a light. This finding is inconsistent with the idea that there is a single clock that times both tone and light durations. If there had been, the birds would have formed an amodal and abstract representation of stimulus duration and the associations between reinforced comparison responses and duration. Consequently, on test trials consisting of the simultaneous presentation of an auditory event and a visual event of equivalent duration, the amodal and abstract representation of that duration should have permitted retrieval of the appropriate response decision regardless of whether comparison stimuli appropriate for an auditory or a visual event were presented.

In addition, the results obtained with the 8-sec tone 2sec light condition are inconsistent with the notion that pigeons have the ability to time several events simultaneously and independently. It has been demonstrated that rats can time simultaneously presented visual and auditory signals independently and without interference (Meck \& Church, 1984). In addition, rats appear to simultaneously time both fixed ITIs and signal durations and use either as a discriminative stimulus for responding (Meck \& Church, 1982). The differences noted here between pigeons and rats in the independent temporal processing of simultaneous events is unlikely to reflect a species difference in their cognitive capacity for parallel processing. As noted previously, both rats and pigeons have been shown to be able to simultaneously process temporal and numerical information (Meck \& Church, 1983; W. A. Roberts \& Mitchell, 1994).

\section{GENERAL DISCUSSION}

A large body of research demonstrates that procedural variations can dramatically affect the assessment of temporal memory in pigeons. These include manipulations of the nature of the discriminative response (Chatlosh \& Wasserman, 1987); the psychophysical method (Fetterman, 1995); choice versus successive DMTS (Grant \& Spetch, 1991; Spetch \& Grant, 1993); ITI (Spetch \& Rusak, 1989, 1992); the mapping of samples to comparison stimuli (Grant \& Spetch, 1993; Santi, Bridson, \& 
Ducharme, 1993); and the nature of the trial outcomes (Ducharme \& Santi, 1993). On the basis of the present findings, the modality of the event being timed and the modality of the choice cues is another important procedural variable that dramatically affects memory for time in both pigeons and rats.

The data from Experiment 1 indicate that there are important differences in the operations of the internal clock for visual and for auditory events. During delay testing for tone duration, a systematic response bias to the comparison stimulus correct for the long duration occurred (i.e., "choose-long errors"). Tests of responding without the tone reduced accuracy on long-sample trials, indicating that the pigeons were attending to the tone and not simply timing the total duration of a trial. Pigeons trained within sessions to match tone and light durations displayed "choose-long errors" following the tone durations and "choose-short errors" following the light durations. These findings are consistent with previous research on rats in which the "choose-long" bias obtained during delay testing was attributed to the nature of the event that stops the internal clock (Santi et al., 1997; Santi et al., 1995). On auditory event duration trials in the present study, the onset of light comparisons in a dark chamber may have overshadowed the offset of the tone and controlled the termination of timing.

The data from Experiment 2 are inconsistent with the idea that a single internal clock times both tone and light durations. They are consistent, however, with the findings of Kraemer (1991). In his study, pigeons were trained in a symbolic matching-to-sample procedure with durations ( 2 vs. $10 \mathrm{sec}$ ) of light and tone mapped onto different visual comparison stimulus sets. Following acquisition of the task, pigeons were presented on test trials with a tone or a light signal and then tested with comparison stimuli appropriate for the modality that had not been presented. Accuracy on test trials involving the shortsample duration remained high, but accuracy on longsample duration trials dropped significantly below chance. These asymmetrical performance deficits are similar to those reported in the present study, and they indicate that equal durations of physically different signals are not functionally equivalent.

Kraemer (1991) noted that one of the critical differences between his study and previous studies that provided evidence for the functional equivalence of durations of physically different signals (Church \& Meck, 1984; S. Roberts, 1982; W. A. Roberts et al., 1989) was that the latter studies trained animals with the same response alternatives for different signal types. In his study, pigeons were trained with different sets of response alternatives (i.e., different comparison stimulus sets) for each signal type tested. The use of different response alternatives also occurred in our study, as well as in a previous study by Durlach and Dawson (1991). Using a peak procedure, Durlach and Dawson trained rats to leverpress in the presence of a light on an FI 32-sec schedule, and to chain-pull on either an FI 8-sec schedule or an FI
128 -sec schedule in the presence of different auditory cues. Rats were then tested with the auditory cues in the presence of the lever and the light in the presence of the chain. To the extent that performance is based on a comparison of elapsed time (from signal onset) with remembered FI time (for that signal), timing behavior should have transferred appropriately when the signal was presented in the context of a different target response. However, timing behavior did not completely transfer, and Durlach and Dawson suggested that response-related cues play an important role in retrieval of information from reference memory.

Behavioral mediation of timing is a defining feature of Killeen and Fetterman's (1988) behavioral theory of timing. According to this theory, signals of differing durations give rise to a series of behavioral states that change probabilistically over time. The behavioral state present at a particular point in time determines whether the instrumental response will occur. The finding that equal durations of physically different signals are not functionally equivalent may be easier for a behavioral theory of timing to account for. Physically different signals of equal duration could result in different adjunctive behaviors that serve as discriminative stimuli for subsequent responses. However, even in Durlach and Dawson's (1991) study, timing behavior was only partly based on the specific response pattern learned for each signal. There was also evidence of control by the time of reinforcement associated with each signal.

The findings of Experiments 1 and 2 are in general agreement with previous reports of attentional dominance of light over tone stimuli in pigeons (Kraemer \& W. A. Roberts, 1985; W. A. Roberts et al., 1989). Greater attention to light signals than to tone signals could account for the significantly higher accuracy of timing with light than with tone in Experiment 1 . It could also account for the finding that pigeons were unable to accurately respond to the duration of the tone when it was simultaneously presented with the light signal in Experiment 2. Differences in the discriminability of sample durations as a function of signal modality need to be considered as a possible factor in the different response biases obtained during delay testing. Grant and Kelly (1996) recently examined the role of sample discriminability in the coding of event duration by pigeons. They reasoned that if sample durations were easy to discriminate, the coding strategy might be biased toward retrospection, and a "choose-short" bias would be observed. However, if sample durations were difficult to discriminate, either because of their duration or because of the signal carrier, then prospective coding (i.e., a representation of the correct comparison response) might occur, and a "choose-short" bias would not be found. Even if tone durations are more difficult to discriminate than light durations, there are two reasons why a memory coding explanation cannot account for our results. First, Grant and Kelly found that "choose-short" effects occur even when the visual signals ( 2 and $3 \mathrm{sec}$ ) are very difficult to 
discriminate. Second, in the present study, a "chooselong" bias was obtained during delay testing with tone, not just the absence of a "choose-short" effect. Consequently, if sample discriminability does play a role, it is not in the coding of event duration in working memory but rather in some other operational feature of the internal clock.

When control by the absolute duration of a signal is relatively weak, as it is with tones, pigeons may also learn about the relationship between the interval from the end of one trial to the opportunity for a choice response on the next trial. The result of the no-tone test in Experiment 1 rules out the possibility that the tone had no control over responding. However, it does not rule out the possibility that responding was controlled by both the tone duration and the total trial duration. Previous research done with rats (Meck \& Church, 1982; Raslear, Shurtleff, \& Simons, 1992) has demonstrated that both the signal duration as well as the total trial duration can be used simultaneously to control responding. Under experimental conditions that promote simultaneous timing of both the total trial duration (ITI plus delay) and the signal duration, response choice at long delay intervals may simply reflect greater control by total trial duration than by signal duration. Future research will be directed at examining the effect of variable ITIs on the timing of tone and light signals, as well as the extent to which the preceding ITI duration affects choice responding as a function of signal modality and duration.

In summary, the present data indicate that there are important differences in the operation of the internal clock for visual and auditory events in pigeons which parallel those previously reported in rats. In addition, the data from Experiment 2 are inconsistent with the idea that there is a single internal clock which times both tone and light durations in pigeons. However, they are consistent with findings reported by Kraemer (1991) and by Durlach and Dawson (1991) which indicate that equal durations of physically different signals are not functionaily equivalent.

\section{REFERENCES}

Allan, L. G. (1979). The perception of time. Perception \& Psychophysics, 26, 340-354.

Berz, S., Battig, K., \& Welzl, H. (1992). The effects of anticholinergic drugs on delayed time discrimination performance in rats. Physiology \& Behavior, 51, 493-499.

BLock, R. A. (1990). Models of psychological time. In R. A. Block (Ed.), Cognitive models of psychological time (pp. 1-35). Hillsdale, NJ: Erlbaum.

Chatlosh, D. L., \& Wasserman, E. A. (1987). Delayed temporal discrimination in pigeons: A comparison of two procedures. Journal of the Experimental Analysis of Behavior, 47, 299-309.

Cheng, K., \& Roberts, W. A. (1989). Timing multimodal events in pigeons. Journal of the Experimental Analysis of Behavior, 52, 363-376.

ChurCH, R. M. (1980). Short-term memory for time intervals, Learning \& Motivation, 11, 208-219.

CHURCH, R. M., \& MECK, W. H. (1984). Acquisition and cross-modal transfer of classification rules for temporal intervals. In M. Commons, A. Wagner, \& R. Herrnstein (Eds.), Quantitative analyses of behavior: Discrimination processes (Vol. 4, pp. 75-97). Cambridge, MA: Ballinger.

DUCHARME, M. J., \& SANTI, A. (1993). Alterations in the memory code for temporal events induced by differential outcome expectancies in pigeons. Animal Learning \& Behavior, 21, 73-81.

DURLACH, P. J., \& DAWSON, G. R. (1991). Response specificity in animal timing. Journal of the Experimental Analysis of Behavior, 55, 11-20.

Fetterman, J. G. (1995). The psychophysics of remembered duration. Animal Learning \& Behavior, 23, 49-62.

FetTerman, J. G. (1996). Dimensions of stimulus complexity. Journal of Experimental Psychology: Animal Behavior Processes, 22, 3-18.

Goldstone, S., \& Lhamon, W. T. (1974). Studies of auditory-visual differences in human time judgments: I. Sounds are judged longer than lights. Perceptual \& Motor Skills, 39, 63-82.

GRANT, D. S., \& KELLY, R. (1996). The role of minimum wait time and sample discriminability in the coding of event duration in pigeons. Learning \& Motivation, 27, 243-259.

Grant, D. S., \& SPETCH, M. L. (1991). Pigeons' memory for event duration: Differences between choice and successive matching tasks. Learning \& Motivation, 22, 180-199.

Grant, D. S., \& SPETCH, M. L. (1993). Analogical and nonanalogical coding of samples differing in duration in a choice-matching task in pigeons. Journal of Experimental Psychology: Animal Behavior Processes, 19, 15-25.

GRONDIN, S. (1993). Duration discrimination of empty and filled intervals marked by auditory and visual signals. Perception \& Psychophysics, 54, 383-394

Killeen, P. R., \& Fetterman, J. G. (1988). A behavioral theory of timing. Psychological Review, 95, 274-295.

KRAEMER, P. J. (1991). Absence of immediate transfer of training of duration symbolic-matching-to-sample in pigeons. Animal Learning \& Behavior, 19, 276-282.

Kraemer, P. J., Brown, R. W, \& Randall, C. K. (1995). Signal intensity and duration estimation in rats. Behavioral Processes, 34, 265-268.

KRAEMER, P. J., RaNdALL, C. K., \& Brown, R. W. (1997). The influence of stimulus attributes on duration matching-to-sample in pigeons. Animal Learning \& Behavior, 25, 148-157.

KRAEMER, P. J., \& RoBerTs, W. A. (1985). Short-term memory for simultaneously presented visual and auditory signals in the pigeon. Journal of Experimental Psychology: Animal Behavior Processes, 11, 137-151.

MANTANUS, H. (1981). Empty and filled interval discrimination by pigeons. Behaviour Analysis Letters, 1, 217-224.

MECK, W. H. (1984). Attentional bias between modalities: Effect on the internal clock, memory, and decision stages used in animal time discrimination. In J. Gibbon \& L. [G.] Allan (Eds.), Timing and time perception (Annals of the New York Academy of Sciences, Vol, 423, pp. 528-541). New York: New York Academy of Sciences.

MECK, W., \& CHURCH, R. M. (1982). Discrimination of intertrial intervals in cross-modal transfer of duration. Bulletin of the Psychonomic Society, 19, 234-236.

MECK, W. H., \& CHURCH, R. M. (1983). A mode control model of counting and timing processes. Journal of Experimental Psychology: Animal Behavior Processes, 9, 320-334.

Meck, W. H., \& ChuRCH, R. M. (1984). Simultaneous temporal processing. Journal of Experimental Psychology: Animal Behavior Processes, 10, 1-29.

MeCK, W. H., CHURCh, R. M., \& Olton, D. (1984). Hippocampus, time and memory. Behavioral Neuroscience, 98, 3-22.

POYNTER, W. D. (1989). Judging the duration of time intervals: A process of remembering segments of experience. In I. Levin \& D. Zakay (Eds.), Time and human cognition: A life-span perspective (pp. 305 . 321). Amsterdam: Elsevier.

Raslear, T. G., ShURTLefF, D., \& Simons, L. (1992). Intertrial-interval effects on sensitivity $\left(A^{\prime}\right)$ and response bias $\left(B^{\prime \prime}\right)$ in a temporal discrimination by rats. Journal of the Experimental Analysis of Behavior, 58, 527-535.

ROBERTS, S. (1982). Cross-modal use of an internal clock. Journal of Experimental Psychology: Animal Behavior Processes, 8, 23-32.

Roberts, S., \& Church, R. M. (1978). Control of an internal clock. 
Journal of Experimental Psychology: Animal Behavior Processes, 4, 318-337.

Roberts, W. A., Cheng, K., \& Cohen, J. (1989). Timing light and tone signals in pigeons. Journal of Experimental Psychology: Animal Behavior Processes, 15, 23-35.

Roberts, W. A., \& Mitchell, S. (1994). Can a pigeon simultaneously process temporal and numerical information? Journal of Experimental Psychology: Animal Behavior Processes, 20, 66-78.

Santi, A., Bridson, S., \& Ducharme, M. J. (1993). Memory codes for temporal and nontemporal samples in many-to-one matching by pigeons. Animal Learning \& Behavior, 21, 120-130.

Santi, A., STANFord, L., \& COYLE, J. (1997). Rats' memory for event duration: Differential effects of delaying the discriminative choice cue as opposed to the opportunity to execute the choice response. $\mathrm{Be}$ havioural Processes, 40, 193-199.

Santi, A., Weise, L., \& Kuiper, D. (1995). Memory for event duration in rats. Learning \& Motivation, 26, 83-100.

SPETCH, M. L. (1987). Systematic errors in pigeons' memory for event duration: Interaction between training and test delay. Animal Learning \& Behavior, 15, 1-5.

SPETCH, M. L., \& Grant, D. S. (1993). Pigeons' memory for event duration in choice and successive matching tasks. Learning \& Motivation, 24, 156-174.
SPETCH, M. L., \& Rusak, B. (1989). Pigeons' memory for event duration: Intertrial interval and delay effects. Animal Learning \& Behavior, 17, 147-156.

SPETCH, M. L. \& RUSAK, B. (1992). Temporal context effects in pigeons' memory for event duration. Learning \& Motivation, 23, 117-144.

SPETCH, M. L., \& WILKIE, D. M. (1982). A systematic bias in pigeons' memory for food and light durations. Behaviour Analysis Letters, 2 , 267-274.

SPETCH, M. L., \& WILKIE, D. M. (1983). Subjective shortening: A model of pigeons' memory for event duration. Journal of Experimental Psychology: Animal Behavior Processes, 9, 14-30.

Stubbs, D. A., Dreyfus, L. R., \& Fetterman, J. G. (1984). The perception of temporal events. In J. Gibbon \& L. [G.] Allan (Eds.), Timing and time perception (Annals of the New York Academy of Sciences, Vol. 423, pp. 30-42). New York: New York Academy of Sciences.

WILKIE, D. M. (1987). Stimulus intensity affects pigeons' timing behavior: Implications for an internal clock model. Animal Learning \& Behavior, 15, 35-39.

(Manuscript received August 22, 1997; revision accepted for publication December 10, 1997.) 